\title{
Cadastro Ambiental Rural como instrumento de gestão do turismo rural em Unidades de Conservação da Natureza
}

\section{Rural Environmental Registry as a rural tourism management instrument in Nature Conservation Units}

\author{
Italo Schelive Correia, Sandro Sidnei Vargas de Cristo, \\ João Paulo Carneiro dos Reis
}

\begin{abstract}
RESUMO: As propriedades rurais em determinadas Unidades de Conservação (UCs) podem se tornar verdadeiros atrativos para a região, favorecendo o turismo ecológico através do turismo rural, enquanto permitem a proteção de uma área ambiental e a sua integração. Apesar de não serem todas as UCs que permitem o turismo rural, as que são permitidas, podem favorecer a integração da UC, carecendo estas de maior atenção das políticas públicas para incentivar as práticas ao mesmo tempo que evitam impactos a UC. Este trabalho tem por objetivo apresentar uma discussão teórica sobre a utilização do Cadastro Ambiental Rural (CAR) como instrumento de gestão e viabilização do turismo rural em Unidades de Conservação da Natureza. Entre os resultados da pesquisa estão elencados os tipos de UCs que permitem a prática do turismo rural e que o uso do CAR colabora com a liberação do turismo rural da propriedade em UCs, bem como com a gestão do turismo rural.
\end{abstract}

PALAVRAS-CHAVE: Cadastro Ambiental Rural; Políticas Públicas; Turismo Rural; Unidade de Conservação.

ABSTRACT: Rural properties in certain Conservation Units (UCs) can become real attractions for the region, favoring ecological tourism through rural tourism, while allowing the protection of an environmental area and its integration. Although not all of the PAs that allow rural tourism, in those that are allowed can favor the integration of the $\mathrm{CU}$, which need more attention from public policies to encourage practices while avoiding impacts to UC. This paper aims to present a theoretical discussion about the use of the Rural Environmental Registry (CAR) as a tool for management and feasibility of Rural Tourism in Nature Conservation Units. Among the results of the research are listed the types of PAs that allow the practice of rural tourism and that the use of CAR collaborates with the liberation of rural tourism from the property in CUs, as well as with the management of rural tourism.

KEYWORDS: Conservation Unit; Public Policy; Rural Environmental Registry; Rural Tourism; Tourism. 


\section{Introdução}

No processo civilizatório o homem encontrou na natureza fonte para suprir as suas necessidades, em um processo histórico evolutivo, chegou a globalização de culturas, e de informações sobre problemas ambientais regionais/locais de diversos níveis de impacto. Esse movimento criou na população mundial uma consciência coletiva sobre a necessidade da preservação/conservação dos recursos naturais por decorrência da sua finitude e esgotamento.

Há registro de que a observação das belezas da natureza já eram descritas por poetas em um movimento ambiental romântico, como reza a lenda popular, certa vez, numa propaganda de venda de terra que o escritor Olavo Bilac fez para seu amigo, fazendo-o desistir da venda, ao ler, e perceber a beleza que sua propriedade possuía:

Vende-se encantadora propriedade onde cantam os pássaros, ao amanhecer, no extenso arvoredo. É cortada por cristalinas e refrescantes águas de um ribeiro. A casa, banhada pelo sol nascente, oferece a sombra tranquila das tardes, na varanda ${ }^{1}$.

Movida pela preocupação universal sobre o uso saudável e sustentável do planeta e de seus recursos, em 1972, a Organização das Nações Unidas (ONU) convocou a Conferência das Nações Unidas sobre o Meio Ambiente Humano, em Estocolmo, na Suécia. O evento foi um marco e sua Declaração final contém 19 princípios que representam um Manifesto Ambiental (ONU, 1972) atual para nossos tempos.

Assim, as principais potências do mundo passaram a se reunir em convenções internacionais para discutir sobre o meio ambiente e os recursos naturais, chegando a um entendimento no relatório "Nosso Futuro Comum", que o desenvolvimento sustentável é "[...] o desenvolvimento que encontra as necessidades atuais sem comprometer a habilidade das futuras gerações de atender suas próprias necessidades" (COMISSÃO MUNDIAL SOBRE MEIO AMBIENTE E DESENVOLVIMENTO - CMMAD, p. 46, 1988).

O Brasil que sempre foi um dos líderes em Unidades de Conservação (UCs) do mundo, por ser um dos países mais ricos em recursos naturais, apresenta em sua Carta Magna, a Constituição da República Federativa do Brasil de 1988 (CFRB/88), o meio ambiente como direito fundamental.

Em 2009, o Brasil tornou-se signatário do Acordo sobre mudanças climáticas da ONU, em que promete frear o desmatamento em todo o seu território nacional, sendo que, para cumprir seu acordo o país deveria reduzir seu desmatamento em até $43 \%$ até 2020 (ROMAN, 2018).

Nesse contexto surge o Cadastro Ambiental Rural (CAR), que conforme o artigo 29 da Lei № 12.651 de maio de 2012:

É um registro público eletrônico de âmbito nacional, obrigatório para todos os imóveis rurais, com a finalidade de integrar as informações ambientais das propriedades e posses rurais, compondo base de dados para controle, monitoramento, planejamento ambiental e econômico e combate ao desmatamento (BRASIL, 2012, art. 29). 
O CAR é uma política pública de meio ambiente que tem por finalidade monitorar as áreas verdes nas propriedades rurais no Brasil, conforme o que pede no Código Florestal Brasileiro (CFB) de $2012^{2}$, que estabelece o mínimo de uma fração de terra dentro das propriedades rurais que deve ser de mata nativa de destinação obrigatória. Apesar de ser tratada como área economicamente inativa por muitos proprietários rurais que usam suas áreas para atividade agropecuária, essas áreas podem ser economicamente ativa se usada de maneira sustentável.

Desta forma, o CAR permite que a propriedade rural explore parte da sua área verde através do turismo, visando descobrir com eficácia as potencialidades econômicas da história, da culinária, das manifestações culturais, da geografia e da hospitalidade do povo da região, gerando emprego e preservando/conservando o meio ambiente em áreas que obrigatoriamente devem permanecer com mata.

Vale destacar a existência de propriedades rurais que se encontram dentro de UCs, que conforme o Sistema Nacional de Unidades de Conservação (SNUC) são:

[...] espaços territoriais e seus recursos ambientais, incluindo as águas jurisdicionais, com características naturais relevantes, legalmente instituídos pelo Poder Público, com objetivos de conservação e limites definidos, sob regime especial de administração, ao qual se aplicam garantias adequadas de proteção da lei (BRASIL, p. 01. 2000).

Dependendo da localização da UC sua exploração é mais restrita que as propriedades que estão em zona livre. O que pode inviabilizar uma exploração econômica de uma atividade agropecuária, deixando a propriedade sem fonte de renda nos moldes que a atividade rural extensiva cobra atualmente.

Para este caso a indicação é o ecoturismo, que normalmente é praticado em áreas protegidas, onde os turistas são levados a cumprirem um conjunto de regras predefinidas com vista à preservação dos ecossistemas no seu estado natural, da sua vida selvagem e da sua população nativa, com a mínima interferência possível.

Portanto, de uma visão geral pautada na legislação vigente a exploração ecoturística de uma propriedade rural que tem seu patrimônio natural bem preservado, pode apresentar uma fonte de renda ao conciliar desenvolvimento econômico e preservação da natureza.

O presente trabalho divide-se em cc capítulos, o primeiro capítulo tem como objetivo mostrar o turismo enquanto um modelo de inovação e gestão social ao desenvolvimento regional, sendo de grande relevância ao crescimento regional sustentável; o segundo capítulo versa considerações cabíveis a análise de viabilidade econômica no turismo rural, invocando algumas discussões sobre o assunto e considera algumas críticas oportunas; o terceiro capítulo apresenta os tipos de Unidades de Conservação (UCs) que permitem o turismo rural.

\section{A mundialização da economia e o impacto no meio ambiente}

A mundialização da economia não conseguiu imprimir ao mundo a importância da preservação do meio ambiente. Vários países estão preocupados 
com o tema, enquanto outros estão adiando os problemas em prol de fortalecimento de suas economias.

Considerando que boa parte dos recursos disponíveis não são renováveis, e milhares de espécimes estão sendo extintas da natureza, não é factoide prever um fim trágico para certos elementos da natureza.

Por isso, a importância de acordos mundiais, com estabelecimento de medidas, metas e compromisso de, ao menos, minimizar os danos já causados, e/ou frear as ações nocivas ao meio ambiente.

Os governos, podem e devem mediante políticas públicas e econômicas fomentar benefícios fiscais, incentivar ações de proteção ambiental para que possam ser cobrados tanto em esfera pública quando no âmbito da sociedade civil via poder judiciário.

Há muitas formas de transformação de bens e recursos naturais em riquezas, portanto, basta apenas implementá-las por meio da legislação existente ou aprimorando-as.

\title{
A viabilidade econômica do turismo rural
}

As comunidades rurais percorrem alguns dilemas a serem destacados, pois estes caracterizam o insucesso na oferta de turismo no meio rural, pode-se dizer que existam para algumas para propriedades nas zonas rurais, uma certa precariedade no fornecimento de serviços públicos, como por exemplo, rodovias, eletricidade, água potável, saneamento ambiental, esgoto, comunicações e sinalização turística.

Todavia, compreende-se, que esta, como outras atividades não fique isenta de riscos, além das dificuldades acima elencadas, e claramente perigosas para algumas localidades. Assim, podemos considerar também que:

\begin{abstract}
Estamos conscientes de que o turismo pode ser uma fonte de oportunidades, mas também é uma ameaça para a coesão social de nossos povos, sua cultura e seu habitat natural. Por este motivo, propiciamos a autogestão do turismo, de modo que nossas comunidades assumam o verdadeiro papel no seu planejamento, operação, fiscalização e desenvolvimento (ORGANIZAÇÃO INTERNACIONAL DO TURISMO, p. 33, 2003).
\end{abstract}

De acordo com Drucker (1998), para diminuir os riscos existentes seria necessário algum planejamento estratégico na uma gestão dos planos frisada pela administração estratégica. Tal planejamento refere-se às escolhas de azimutes a seguir, ou conquistas para fazer; traçando planos entrelaçados a métodos previamente traçados.

Contudo, não se pode elencar planejamentos sem que haja antes de tudo uma pesquisa, onde possam ser abstraídos todos os dados que importem e que oferecem subsídios de foco, para se trabalhar projetos capazes de surtir efeitos maximizadores sociais além do econômico. 
Além disso, Drucker (1998) destaca que, outros fatores econômicos importantes para a região explorada, o turismo em si, é entendido como uma atividade de entretenimento, que movimenta milhões ao redor do mundo e emprega formalmente milhares de pessoas. Contudo, esta atividade pode oferecer mais que isso ao universo rural.

Desta forma, podem-se oferecer oportunidades de ganhos intelectuais e sociais através do contato com diferentes culturas e costumes da zona rural. Por isso, é uma atividade constantemente incentivada entre os locais com potencial ecológico. Entende-se a partir de Tenório (2007) que, em qualquer parte do mundo, ou em qualquer lugar que se pretenda ir, o ambiente rural possui um certo impacto para a economia da comunidade que o explora.

Continuamente, para alguns locais específicos, tais atividades constituem-se na principal fonte de renda. Todavia, a sua importância não atinge apenas esta via econômica, mas também social (GUIMARÃES, 2000).

Neste mesmo entendimento, a história nos mostra que é possível alavancar um considerável desenvolvimento social a partir das atividades do turismo nas comunidades rurais:

Em 1963, a ONU recomendou que fosse ofertada prioridade à assistência técnica no setor do turismo, devido a sua grande importância como via de reforço da política de crescimento econômico nos países em desenvolvimento, isto porque o turismo estimula os investimentos, constitui-se como um meio de aquisição de moeda estrangeira, e uma fonte de criação de emprego, estimula a mobilidade social e a requalificação de profissionais para as necessidades de serviços derivados do turismo (ROUSSEL, 2006, p.1).

Contudo, é necessário ater que o turismo rural, sendo diferenciado do turismo mais formal que movimenta as grandes metrópoles, e basicamente construído em pequenas cidades com grandes potencialidades, como promover ação e aprendizado coletivos com relação ao respeito para com a natureza.

Neste lócus, Guimarães (2000) incrementa deva-se considerar a informalidade habitual do mercado de trabalho, considerando, em parte, como resposta à falta de emprego. Além disso, às vezes é realizada de forma desorientada, e formada por células descompromissadas de sentido solidário. Portanto, com ou sem muito potencial para sobreviverem a eventuais crises. Requerer-se, desta forma, que haja mecanismos motivadores para a formação de um tecido social mais homogêneo, ou seja, um grupo.

Observa-se o turismo de base rural em pequenas cidades em função de uma gestão, com objetivo social e econômico, em que as expressões, de um modo geral, devam conduzir o grupo às relações de solidariedade e pertencimento (RAZETO, 1993).

Entretanto, sem a atuação direta do poder público, as dificuldades econômicas para este tipo de turismo podem ser muitas, principalmente nas regiões nordestinas, mais distantes das zonas metropolitanas. A infraestrutura de apoio, além de escassa e precária pode apresentar dificuldades de financiamento para a 
sua evolução local, para que o turismo regional avance como oportunidade de desenvolvimento e renda sustentável.

Ao abordar estudos sobre as políticas públicas de turismo, além do conceito, torna-se cabível algumas breves considerações a respeito da interferência do poder do Estado na iniciativa privada para movimentar o turismo, apoiando e construindo ideias de desenvolvimento regional. A iniciativa da qual se fala, imagina-se, ser em grande parte do próprio comercio local, para a atração de visitantes em qualquer localidade, e acessível a receber propostas, estudos, projetos ou mesmo programas que busquem qualquer melhoria neste setor, desta forma:

[...] tem sido objeto de estudo e prática muito mais associado à gestão de políticas sociais, de organizações do terceiro setor, do combate à pobreza e até ambiental, do que à discussão e possibilidade de uma gestão democrática, participativa, quer na formulação de políticas públicas, quer naquelas relações de caráter produtivo (TENÓRIO, 2007, p. 147-148).

Neste sentido prático, as instituições de ensino superior também podem contribuir com a população local, o que ocorrerá não somente através de oportunidades de conhecimento, mas também em atividades puramente práticas e inovadoras (RAZETO, 1993).

Adiante, a viabilidade de operacionalizar uma fonte econômica solidária depende não somente da vontade do grupo, mas também da oportunidade de realizar parcerias com instituições que já atuam neste processo.

Desta forma, o Turismo de base Rural possui expressões que o identificam como um fenômeno de gestão social, economia, ecologia e agroecologia ${ }^{3}$, cabendo apenas descrever adiante como esta atividade funciona enquanto economia solidária, e se articula na compreensão e identificação própria dos seus participantes.

\section{Os impactos socioeconômicos do turismo rural}

Têm-se conhecimento de turismo rural desde a década de 1950, sendo os Estados Unidos e a Europa precursores na área. O programa leader da União Europeia foi material de referência nas políticas de gestão do turismo rural, entre outras atividades que se permeiam no meio rural não-agrícolas (BRASIL, 2008).

Desta forma, países da América Latina vêm desenvolvendo atividades que buscam incentivar o turismo como forma de incentivo ao trabalho local, que buscam promover os patrimônios naturais e históricos. Países como Chile, Argentina e Uruguai, são exemplos de aumento de turismo e gerenciamento de serviços, nesta seara:

No Brasil, embora a visitação a propriedades rurais seja uma prática conhecida em algumas regiões, apenas na década de 1980 passou a ganhar status de atividade econômica. Nessa época, começou a ser encarada com profissionalismo e caracterizada como Turismo Rural, quando algumas propriedades em Santa Catarina e no Rio Grande do Sul, principalmente devido às dificuldades do setor agropecuário, 
resolveram diversificar suas atividades e receber turistas. Desde então, esse segmento vem crescendo gradativamente nas diferentes regiões do Brasil, favorecido pelas singularidades dos ciclos econômicos que as marcam e pela diversidade cultural resultante dos processos de colonização (BRASIL, p.15, 2010).

O turismo rural é uma atividade econômica que proporciona a diversidade no comércio regional, em que se estabelecem microempreendedores que ao gerenciar suas atividades melhoram a condição de sua comunidade, em geral, há uma diminuição do êxodo rural e uma troca de culturas. Isso desencadeia uma melhoria na vida dos que ali desempenham suas atividades, seja no transportem comunicação e/ou saneamento. Com isso, a melhoria social provocada, desenvolve uma identidade campesiana.

Contudo, é preciso atentar, também, para as questões negativas de uma implantação mal planejada, como a sobrecarga da estrutura rural quanto a quantidade de visitações, problemas legais, degradação ambiental e descaracterização do meio e da própria atividade, ou seja, perda da particularidade local.

\section{O turismo rural e sua relevância ao desenvolvimento local}

O turismo de base rural é capaz de expressar grande capacidade no turismo regional. Configura-se justificável o estudo de expressões de solidariedade econômica rural, e qual a dinâmica deste tipo de turismo local, além de subtrarir destes contextos sociais e de outros dados para uma compreensão de sua sustentabilidade.

O turismo rural pode ser entendido enquanto setor de oportunidades econômicas e sociais, além de reconhecido como importante gerador de divisas, oportunizando emprego e renda, e contribuindo para redução das desigualdades regionais e sociais em diferentes pontos do nosso território. Sua visibilidade pode ser estudada enquanto fenômeno social, e adiante, pode-se encontrar neste estudo, alguns traços de cunho econômico e social que o configuram enquanto categoria elementar.

Desta forma, tem-se que esta gestão social, pois:

[...] se caracteriza como um novo modelo frente à onda neoliberal capitalista. Apesar de ser - e ter - um conceito ainda em construção, nos ateremos, para fins deste trabalho, à gestão social entendida como um modelo de gestão oriundo das perspectivas (NASCIMENTO, 2013 apud FRANÇA FILHO, p.37, 2003).

Observando na prática este conceito, e entendidas em suas intimas relações de parceria, principalmente quando se localizou a existência de associações formais com a dos artesãos, unidos e organizados na colaboração para que municípios não deixassem de ser visitados pelos turistas potencias, identificando-se como uma gestão social, já que configura-se um: 
[...] ato relacional capaz de dirigir e regular processos por meio da mobilização ampla de atores na tomada de decisão (agir comunicativo) que resulte em parcerias intra e inteorganizacionais, valorizando as estruturas descentralizadas e participativas, tendo como norte o equilíbrio entre a racionalidade em relação a fins e em relação a valores, alcançar enfim um bem coletivamente planejado, viável e sustentável a médio e longo prazo. O que se exige do gestor, então, é que ele tenha visão de conjunto, ajude na transformação sociocultural, mas também simbólico-valorativa, e que se mantenha vigilante ante os mecanismos de auto-regulação (FISCHER, 2003, p.2).

Organicamente, o turismo rural geralmente é desenvolvido através de uma gestão social, um tipo de administração, em que podem ser também visualizados alguns de seus exemplos no Plano Nacional do Turismo (2018-2022), ferramenta de planejamento e ação estratégica governamental, e que serve como subsídio para estruturação e ordenamento do turismo, respeitando-se os princípios da sustentabilidade econômica, ambiental, sociocultural e político-institucional (BRASIL, 2018).

De acordo com o França Filho (2003), até podemos pensar a gestão social que se realiza no Turismo enquanto meio, isto é, enquanto processo de construção e conceber a gestão dentro da tradição administrativa, ou seja, de forma organizada em fases (início, meio e fim) dando-Ihe organização a fim de que não se desvie do seu verdadeiro sentido.

Em vista de seu caráter único, Maldonado (2009) também descreveu que diversas comunidades estariam se abrindo para o mercado formal graças ao que ele denominou de "turismo com selo próprio", combinando atributos de pertencimento e autenticidade, mas sem perder a sua essência.

É necessário, contudo, identificar algumas categorias de economia social no turismo rural local, o qual, de um modo geral, não pode ser considerado como um mar de rosas. Pautando-se nesta afirmação popular, pode-se enumerar outras considerações de Maldonado (2009), principalmente quando se colocam fatores como uma oferta dispersa e fragmentada, às vezes, carente de estruturação e mecanismos regulares de cooperação interna para sua organização e externa para sua potencialização. Além disso, observa-se que possa haver certa escassez nos produtos turísticos cujos componentes sejam exclusivamente fatores naturais e herdados; capítulo quatro sobre a agroecologia e sua importância significa a sustentabilidade local através da conservação do patrimônio ambiental.

\section{Tipos de Unidades de Conservação (UCs)}

As UCs dividem-se em dois grupos: As Unidades de Conservação de Proteção Integral e as Unidades de Conservação de Uso Sustentável.

Nas Unidades de Proteção Integral a proteção da natureza é o principal objetivo dessas unidades, por isso as regras e normas são mais restritivas. Nesse grupo é permitido apenas o uso indireto dos recursos naturais; ou seja, aquele que não envolve consumo, coleta ou danos aos recursos naturais. Exemplos de atividades de uso indireto dos recursos naturais são: recreação em contato com a 
natureza, turismo ecológico, pesquisa científica, educação e interpretação ambiental, entre outras. As categorias de proteção integral são: estação ecológica, reserva biológica, parque, monumento natural e refúgio de vida silvestre.

Por sua vez, as Unidades de Uso Sustentável são áreas que visam conciliar a conservação da natureza com o uso sustentável dos recursos naturais. Nesse grupo, atividades que envolvem coleta e uso dos recursos naturais são permitidas, desde que praticadas de uma forma que a perenidade dos recursos ambientais renováveis e dos processos ecológicos estejam assegurados. Exemplos de atividades de uso direto dos recursos naturais: Artesanato de capim-dourado, coco e palha de babaçu, extração de produtos alimentícios, tais como pequi, cajá, açaí, etc. As categorias de uso sustentável são: área de relevante interesse ecológico, floresta nacional, reserva de fauna, reserva de desenvolvimento sustentável, reserva extrativista, área de proteção ambiental (APA) e reserva particular do patrimônio natural (RPPN).

\section{O Cadastro Ambiental Rural e a gestão e monitoramento da propriedade rural}

O Cadastro Ambiental Rural (CAR) é um registro público eletrônico de âmbito nacional, declaratório e obrigatório para todos os imóveis rurais, com a finalidade de integrar as informações ambientais das propriedades e posses rurais. Foi instituído pelo Código Florestal Brasileiro, Lei № 12.651/2012, e é um registro georreferenciado das informações ambientais das propriedades e posses rurais de todo o país.

A inscrição no CAR é o primeiro passo para obtenção da regularidade ambiental do imóvel, e contempla: Dados do proprietário, possuidor rural ou responsável direto pelo imóvel rural; Dados sobre os documentos de comprovação de propriedade e ou posse; e, Informações georreferenciadas do perímetro do imóvel, das áreas de interesse social e das áreas de utilidade pública, com a informação da localização dos remanescentes de vegetação nativa, das Áreas de Preservação Permanente, das áreas de Uso Restrito, das áreas consolidadas e das Reservas Legais (BRASIL, 2016).

As informações declaradas no CAR servirão como base de dados para controle, monitoramento, planejamento ambiental e econômico e combate ao desmatamento. Haverá restrição, caso a obrigatoriedade não seja cumprida: a partir de 01/01/2019, proprietários e possuidores de propriedades rurais precisarão da inscrição no CAR para ter acesso a crédito e seguro agrícola.

Em contrapartida, haverá vantagens e benefícios para o proprietário rural inscrito no CAR, dentre várias outras tem-se: a) melhores condições para atividades "agrossilvipastoris, de ecoturismo e de turismo rural em áreas rurais consolidadas até em 22 de julho de 2008" estas áreas localizadas nas "Áreas de Preservação Permanente e Reserva Legal"; e b) Melhores condições para que seja autorizado em sua propriedade a intervenção e supressão de vegetação em Áreas de Preservação Permanente e de Reserva Legal, desde que essas atividades sejam de um baixo impacto ambiental (BRASIL, 2012). 


\section{Exploração econômica e sustentabilidade}

É necessário a adoção de medidas ecologicamente corretas com a finalidade de preservar no presente para não faltar no futuro. Tais medidas são de responsabilidade tanto do governo quanto da sociedade civil em geral, para a construção de uma realidade pautada na sustentabilidade.

Aponta-se como medidas para sustentabilidade, a demarcação e fiscalização das áreas de proteção ambiental, reservas e unidades de conservações de matas ciliares. Nos casos de infração pela degradação do meio ambiente, devem ser tomadas medidas para que se proceda a recomposição da área prejudicada. Além disso, dar tratamento adequado ao lixo urbano e rural, reduzir as queimadas e mostrar às crianças a importância e o respeito que se deve dispensar à natureza.

\section{O Ecoturismo e agroecologia no turismo rural}

O ecoturismo faz parte do turismo rural e sua importância significa a sustentabilidade local através da conservação do patrimônio ambiental.

A agroecologia pauta-se em princípios básicos que de acordo com o Freitas e Blanco, dividem-se em:

Assegurar as condições de vida do solo que permitam a manutenção de sua fertilidade e o desenvolvimento saudável das plantas, por meio de práticas como: Cobertura permanente do solo (viva ou mülching); Adubação verde; Proteção contra os ventos,; Práticas de conservação do solo (controle da erosão); Rotação de culturas, ; Consorciação de culturas, Cultivo em faixas, entre outras. Usar espécies ou variedades adaptadas às condições locais de solo e clima, minimizando exigências externas para um bom desenvolvimento da cultura. Assegurar uma produção sustentável das culturas sem utilizar insumos químicos que possam degradar o ambiente, fazendo uso da adubação orgânica, de produtos minerais pouco solúveis (fosfato de rocha, calcário, pó de rocha, etc) e de um manejo fitossanitário que integre as práticas culturais, mecânicas e biológicas para 0 controle de pragas e doenças. Diversificar as atividades econômicas da propriedade, buscando a integração entre elas para maximizar a utilização dos recursos endógenos e assim diminuir a aquisição de insumos externos à propriedade. Favorecer a auto-gestão da comunidade produtora respeitando sua cultura e estimulando sua dinâmica social (FREITAS; BLANCO, s.p., 2010).

Justifica-se a defesa do ecoturismo, pelo fato de que a sociedade carece de melhorias relativas quanto a proteção ambiental, uma vez que estudos dos principais institutos de pesquisas estatísticas apontam pela necessidade de melhorias sobre 0 mesmo fulcro. Além disso, Andrade (1997) descreve que, faz-se necessário descrever e emitir sugestão de estratégias e técnicas inovadoras ao meio ambiente, sendo primordial para a resolução de problemas ambientais. Todavia, ainda servem de apoio técnico, consultas e pesquisas de subsídio técnico.

No Brasil, inicialmente, a preocupação se fazia na preservação da natureza em função de interesses econômicos. Logo após a proclamação da independência, tais objetivos ainda continuaram os mesmos. Na década de 1930, do século 20 , 
foram realizadas algumas modificações, para delinear o estabelecimento de um Código Florestal e do chamado Código das Águas. Na década de 1970 entendida como a década da regulamentação e controle ambientais. Imediatamente, logo após a Conferência de Estocolmo, outras nações começaram a estruturar seus órgãos ambientais e do estabelecimento de suas legislações, e visar ao controle de poluição ambiental (ANDRADE, 1997).

Outrossim, a Conferência de Estocolmo passou a influenciar toda a sociedade brasileira, em 1973, os anseios da população culminaram na criação da Secretaria Especial do Meio Ambiente - SEMA, que assumiria a função de estabelecimento das normas e de padrões com relação à preservação do meio ambiente. Já na década de1980, entrou em vigor legislações específicas que perseguiam o objetivo de controle da instalação de novas indústrias e ao estabelecimento das exigências relativas ao controle de emissões das indústrias existentes (ANDRADE, 1997).

Adiante, em 1981, Congresso Nacional sancionou a Lei n. 6.938/1981, que estabeleceu um nova Política Nacional para o Meio Ambiente, cuja previsão descentralizava ações e atribuições dos Estados e Municípios, para a função executar medidas e demais providências com finalidade de oferecer proteção ao meio ambiente (OLIVEIRA, 2009).

Em seguida, Oliveira (2009) ressalta que, ao final da década de 1980, aumentava-se a preocupação com a conservação dos espaços do meio ambiente. 0 "Protocolo de Montreal", editado em 1987, excluía um extenso rol de produtos químicos (os clorofluorcarbonos ou CFC's) e estabelecia prazos na substituição destes. O "Relatório oferecido pela Comissão Mundial sobre o Meio Ambiente e Desenvolvimento", instituída pela Assembleia Geral das Nações Unidas.

Logo depois, a CRFB/88, através do artigo 225 ordenava que:

Todos têm direito ao meio ambiente ecologicamente equilibrado, bem de uso comum do povo e essencial à sadia qualidade de vida, impondo-se ao Poder Público e à coletividade o dever de defendê-lo e preservá-lo para as presentes e futuras gerações. (BRASIL, 1988, art. 225).

Na década de 1990, percebeu-se que a população brasileira passou a se preocupar mais com a manutenção do equilíbrio ambiental e do efeito nocivo dos resíduos quando ultrapassavam os limites da área em que havia sido gerada ou disposta (OLIVEIRA, 2009).

O autor Andrade (1997) aponta que, no ano de 1992, ocorreu a "Conferência das Nações Unidas sobre o Meio Ambiente e Desenvolvimento", ou Rio-92, realizada na cidade do Rio de Janeiro. Resultando na Carta da Terra, conhecida como Declaração do Rio, e a Agenda 21. Ainda na década de 1990 as normas britânicas BS 7750 - Specification for Environmental Management Systems (Especificação para Sistema de Gestão Ambiental), lançou a série ISO 14000, e a série ISO 9000, que constituem o coroamento de lutas para conservação do meio ambiente (OLIVEIRA, 2009).

O problema atenuante, trata-se da gestão ambiental ser conduzida pelo planejamento de estratégias impostas na sociedade brasileira, tem sido o motivo de discussão teórica nos últimos tempos. Apesar de várias pesquisas fundamentadas a 
respeito de seu funcionamento, a sociedade precisa debater tal temática de forma mais crítica (TURBAN, 2005). Com fulcro pautado sob a perspectiva crítica, e correlacionado com os sistemas sociais que indicam interferências no seu contexto histórico e suas adaptações em função da necessidade humana (LEICHENKO; O'BRIEN; SOLECKI, 2010).

No que diz respeito a sua viabilidade econômica, e muito se especulou a esse respeito nas últimas décadas, alguns autores creditam considerações antagônicas de que seu valor seja modificado em paridade com as mudanças de contexto econômico.

Isto posto, a discussão que Andrade (1997) percorre, indica a contextualização histórica e da gestão do ecoturismo, conduzida pelo planejamento de estratégias, perpassando a necessidades de ajustes e ao mesmo tempo um considerável controle de seu planejamento e metodologia, os quais recorreriam a utilização, análise e a atualização, devido aos dados fornecidos pelos censos populacionais que são paulatinamente renovados pelo Instituto Brasileiro de Geografia e Estatística (IBGE) a cada 10 (dez) anos.

Nesse sentido, cabe apontar que os governos brasileiros têm informado em seus relatórios de gestão que, que por vários anos tenta-se estabelecer metas que contribuam com ecoturismo rural, e entende-se a partir de Turban (2005), que aponta a gestão no ecoturismo a ser conduzida pelo planejamento de estratégias, e limitando-a diante do contexto demográfico brasileiro, desta forma, é entendido em síntese no problema de crescimento de demandas sem acompanhamento estatal.

Como estratégia para atendimento, dos problemas supracitados, em todo o território devido, a exploração do ecoturismo nasce a oportunidade da administração que cuida dessa oferta, atuar sob influência do crescimento de demandas relativas ao seu atendimento e prestação de serviços (OLIVEIRA, 2009).

Nota-se portanto, que para o sucesso de tal trabalho, é adequado reler mais profundamente o contexto histórico na linha econômica, social e legislativa da sistemática governamental da população brasileira, principalmente, sobre as mudanças políticas implementadas nos últimos anos, que diminui os orçamentos para a fiscalização do ecoturismo realizada através do governo com uso do Cadastro Ambiental rural.

\section{O caminho de volta para a roça}

A vida agitada da cidade, com o trânsito, a violência, as filas de banco, escritórios com ambientes fechados, apartamentos pequenos, aglomeração de pessoas: diante do stress da vida nos centros urbanos, muitas pessoas sentem a necessidade de fazer o caminho de volta para a roça, para recarregarem suas energias em um ambiente natural, rústico, em conexão com os animais, as plantas e a rotina da vida campesina.

Atualmente o serviço de turismo rural está disponibilizado em todos os estados brasileiros, e pelo menos por algumas horas ou dias, o turista pode se deligar da correria e relembrar ou experimentar outras formas de vivência por meio do turismo rural. 


\section{O modelo de ecoturismo sustentável do Recanto Ecológico Rio da Prata (Jardim, MS)}

Como modelo de estudo de caso tem-se o que foi desenvolvido na Fazenda Cabeceira do Prata, em que:

[...] o atrativo de ecoturismo Recanto Ecológico Rio da Prata, está localizada no município de Jardim, Sudoeste do estado de Mato Grosso do Sul, distante $36 \mathrm{~km}$ da cidade de Jardim, $49 \mathrm{~km}$ de Bonito e $270 \mathrm{~km}$ de Campo Grande, a capital do Estado. Fica nos limites da região da Serra da Bodoquena, dentro do Corredor de Biodiversidade Miranda - Serra da Bodoquena, região que faz parte da zona núcleo da Reserva da Biosfera do Pantanal, ou seja, são áreas prioritárias para a conservação de biodiversidade dos biomas do Cerrado e Pantanal. Em 1979, a fazenda foi comprada por Eduardo Folley Coelho com objetivos de lazer e pecuária. Desde a aquisição da fazenda, foram adotadas medidas para conservação ambiental, como manejo adequado do solo, visando à prevenção de erosão, manejo da pastagem sem o uso de queimadas, construção de curvas de nível e açudes e início da recuperação das áreas de mata ciliar por meio do plantio de árvores nativas. Nessa nova etapa, não foram derrubadas nenhuma árvore para a construção de cerca e instalações. Só se utilizaram postes de madeira já cortados e refugados pelo proprietário anterior, árvores caídas, e também madeira de outras propriedades da família." (Associação Brasileira das Operadoras de Turismo (BRAZTOA, p. 19, 2012).

É importante destacar que a visitação turística possui seus riscos, principalmente para a natureza, rogando pelo cuidado que deve ser realizado na visitação, sendo que os municípios devem possuir aparato para isso (BRAZTOA, 2012).

O estudo deste caso desvendou diversos fatores, entre eles a preservação da mesma paisagem.

É nítido que:

"A visitação turística foi iniciada em 1995 e consiste em uma trilha pelas matas ciliares dos rios da Prata e Olho d'Água, chegando até a nascente do rio Olho d'Água, local de rara beleza, a partir do qual um grupo de no máximo nove pessoas desce flutuando um trecho de cerca de dois mil metros de águas cristalinas, equipadas com máscaras, snorkel, botas e roupas de neoprene. A propriedade ainda oferece mergulho com cilindro, passeio a cavalo e um roteiro para a observação de aves. O limite diário de visitantes no passeio de flutuação é de 150 pessoas, preconizado pela Licença Ambiental do empreendimento. Todos os grupos são conduzidos por guias credenciados pelo Ministério do Turismo, pertencentes às comunidades locais, treinados para passar segurança e informações ambientais durante a atividade. A infraestrutura principal é formada pela sede da fazenda onde se localizam recepção, restaurante, bar, cozinha, escritório administrativo, loja de artesanato regional, sala de equipamentos e área de descanso para os visitantes. Não há hospedagem no local." (BRAZTOA, p.19, 2012). 
Diversas são as atividades turísticas que podem ser desenvolvidas na região e no âmbito das propriedades rurais, conforme as sugeridas no Manual: turismo rural (2008), elencadas abaixo:

a) Serviços e equipamentos turísticos: serviços, edificações e instalações indispensáveis ao desenvolvimento da atividade turística e que existem em função desta. Importante lembrar que é recomendável incentivar empresas da área ao cadastro junto ao Ministério do Turismo pelo sistema do Cadastur. Hospedagem estabelecimentos que oferecem alojamento e serviços necessários ao conforto do hóspede. No caso do Turismo Rural, pode caracterizar-se como pessoa física ou jurídica e compreende a hotelaria tradicional/convencional, a hospedagem domiciliar ou em "casas de família", pensões, hotéis, alojamentos, pousadas, campings etc. Alimentação - a gastronomia é um elemento muito valorizado pelo turista que procura o meio rural. No Turismo Rural ela pode ser oferecida: a) Na região: estabelecimentos que oferecem ao turista refeições, lanches, bebidas, alimentos em geral e demais serviços complementares. Ex.: restaurantes, lanchonetes, cafés, bares, quiosques etc. b) Nas propriedades: almoço e café colonial, gastronomia típica, produtos caseiros, entre outros (BRASIL, p.26, 2008).

Ademais, o manual aponta que a função ou emprego de guia do turismo deve ater-se a normas do referido $\mathrm{Manual}^{4}$, em face também são indicadoras de riscos para com a natureza e na possibilidade de colaboração com o governo em face da preservação doa ambientes.

O manual fala neste sentido que:

Guiamento, condução e recepção - atendimento e orientação ao turista individualmente ou em grupo, via centro de informações turísticas, agências e operadoras de turismo receptivo, guias e condutores locais. Transporte no local - serviços específicos para deslocamento no destino (ônibus de excursão, vans, carro próprio ou disponibilizado pelas prefeituras ou órgãos locais e também os serviços contratados pelos agentes operadores). Inclui também o serviço de transporte ofertado diretamente pelas propriedades rurais para fazer os traslados. Os serviços e equipamentos de transporte turísticos têm a finalidade específica de realizar excursões e outras programações turísticas (BRASIL, p. 26, 2010).

Além disso, atividades como os "pesque e pagues" e outras formas de entretenimento, que são muito exploradas no nicho do turismo rural passaram a receber a devida normatização, neste sentido o Manual identifica a atividade da seguinte forma:

[...] pesca - compreende a pesca esportiva e a prática da pesca amadora. Ex.: pesque-pague, pesca em rios, lagos naturais, represas etc. De aventura - atividades recreativas que envolvem riscos controlados e assumidos. Ex.: arvorismo (arborismo), bóia-cross, rapel, tirolesa e vários outros. De esporte - compreendem os jogos e 
disputas competitivas, no âmbito amador, com a presença de regras estabelecidas pela prática de modalidades esportivas. Ex.: corridas a cavalo, prática de ciclismo, caminhadas etc.

Atividades ecoturísticas - atividades de interação com a natureza, que incentivem 0 comportamento social e ambientalmente responsável. Ex.: trilhas, observação da fauna (pássaros, borboletas, jacarés, peixes) e da flora (espécies vegetais nativas, parques, etc.) estão entre as possibilidades. Atividades pedagógicas - atividades de cunho educativo que auxiliam no processo ensino-aprendizagem, comumente promovidas por escolas e realizadas pelos respectivos grupos de estudantes. Ex.: aulas práticas interpretativas do ambiente, palestras informativas, vivências e experiências variadas nos ambientes visitados, incluindo participação em colheitas, ordenhas, trato de animais etc. Atividades culturais - atividades destinadas a proporcionar a vivência dos aspectos culturais mais significativos da região - para fins de conhecimento, contemplação e entretenimento, principalmente. Podem ser relacionadas aos seguintes atrativos: Manifestações populares - acontecimentos ou formas de expressão relacionados à música, dança, folclore, saberes e fazeres locais, práticas religiosas ou manifestações de fé. Ex.: rodas de viola, folia-de-reis, crenças, rezas, missas etc. Artesanato objetos produzidos manualmente ou com equipamentos rudimentares, em pequena escala, característicos da produção de artistas populares da região, utilizando matéria-prima regional. Arquitetura típica ou histórica - contempla as construções típicas do campo (açude, capela, curral etc.), as técnicas e materiais construtivos peculiares ou com materiais da região (pau-a-pique, sapé e outros) e as construções históricas. Museus/casas de cultura - locais destinados à apresentação e conservação de objetos de caráter cultural ou científico. Ex.: Museu da Cachaça, Museu do Folclore etc. Gastronomia - conjunto de alimentos e bebidas ofertados que representam as tradições culinárias da região. Atividades recreativas - compreendem jogos e brincadeiras, com a função de diversão e entretenimento, além de equipamentos destinados a essa finalidade. Ex.: jogos de tabuleiro, rodas cantadas, bingos; e de equipamentos como piscinas, quadras esportivas etc. (BRASIL, p. 34, 2010).

Assim, verifica-se que toda a didática sugestionada pelo manual que coloca nesta síntese todo o esboço necessário ao entendimento das possibilidades e conceitos que devem ser comumente observados para o turismo rural.

\section{Considerações finais}

Desta forma, levantou-se por meio deste estudo a necessidade de se pensar em estratégias para criar ou aumentar a fonte de renda dos campesinos, proporcionando desenvolvimento local sustentável, no turismo rural.

Percebeu-se que até mesmo as propriedades rurais que estão em Unidades de Conservação podem fazer uso do patrimônio natural que possuem para garantir sua viabilidade econômica. 
Neste contexto, o turismo rural pode ser encarado como uma opção dos pequenos proprietários rurais para diversificar e aumentar sua fonte de renda, proporcionando renda e interação entre cidade e campo, nos mais diversos afazeres: atividades diretas e indiretas relacionadas ao meio ambiente. Na razão de poder oferecer ideias inovadoras ao crescimento regional, o turismo rural é consideravelmente oportuno em tempos de crise financeira, e deve ser plenamente incentivado, devido a seu caráter cidadão.

Contudo, é necessário que o proprietário possuidor esteja devidamente cadastrado no CAR, para que possa ter os benefícios de créditos bancários para prover seu investimento e contar, ainda, com o incentivo público, no sentido de manter acessos para deslocamentos, segurança de visitantes, para que a região receba incentivos do poder públicos.

Todavia, o desenvolvimento sustentável, se tratado com responsabilidade, pode trazer benefícios tanto para os campesinos quanto para os visitantes, ao mesmo tempo que aumenta a visão e desperta as pessoas para a necessidade de uso consciente de recursos e através de uma política econômica, que considere não o custo da preservação, mas a importância dos ecossistemas, para se cumprir, em outras palavras, o almejado no relatório nosso futuro comum (CMMAD, 1987): O desenvolvimento que satisfaz as necessidades presentes, sem comprometer a capacidade das gerações futuras de suprir suas próprias necessidades.

\section{Referências}

ANDRADE, J.C.S. Desenvolvimento sustentado e competitividade: tipos de estratégias ambientais empresariais. ECBAHIA R. Baiana. Tecnol., Camaçari, v.12, n.2, maio/ago.1997. Disponível em: <https://silo.tips/download/desenvolvimentosustentado-e-competitividade>. Acesso em: 10 set. 2020.

Associação Brasileira das Operadoras de Turismo. BRAZTOA (org.). Melhores práticas de turismo sustentável: Coletâneas dos cases vencedores do Prêmio Braztoa de Sustentabilidade. Senac. 2012. Disponível em: $<$ https://www.sp.senac.br/pdf/56109.pdf $>$. Acesso em: 09 set. 2020.

BRASIL, Ministério da Cultura. Lei no 6.938, de 31 de agosto de 1981. Dispõe sobre a Política Nacional do Meio Ambiente, seus fins e mecanismos de formulação e aplicação, e dá outras providências. Disponível em: $<$ http://www.planalto.gov.br/ccivil 03/leis/L6938.htm>. Acesso em: 10 set. 2020.

BRASIL. Lei no 12.651, de 25 de maio de 2012. Dispõe sobre a proteção da vegetação nativa e dá outras providências. Disponível em: $<$ http://www.planalto.gov.br/ccivil 03/ Ato2011-2014/2012/Lei/L12651.htm>. Acesso em: 10 set. 2020.

BRASIL. Ministério da Agricultura e Meio Ambiente. O que é o Cadastro Ambiental Rural (CAR). 2016. Disponível em: <http://www.florestal.gov.br/o-que-e-ocar\#: :text=A\%20inscri\%C3\%A7\%C3\%A30\%20no\%20CAR\%20\%C3\%A9,do\%20im \%C3\%B3vel\%2C\%20das\%20\%C3\%A1reas\%20de>. Acesso em: 10 set. 2020.

BRASIL. Ministério do Turismo. Plano Nacional de Turismo - 2018-2022: "Mais emprego e renda para o Brasil". Disponível em: $<$ http://www.turismo.gov.br/images/pdf/PNT 2018-2022.pdf>. Acesso em 09 set. 2020. 
BRASIL. Ministério do Turismo. Turismo rural: orientações básicas. / Ministério do Turismo, Secretaria Nacional de Políticas de Turismo, Departamento de Estruturação, Articulação e Ordenamento Turístico, Coordenação Geral de Segmentação. - 2. ed - Brasília: Ministério do Turismo, 2010.

BRASIL, Ministério do Turismo, Secretaria Nacional de Políticas de Turismo, Departamento de Estruturação MTUR. Manual: Turismo rural: orientações básicas., Articulação e Ordenamento Turístico, Coordenação Geral de Segmentação. - Brasília: Ministério do Turismo, 2008. 53 p.

BRASIL. Constituição (1988). Constituição da República Federativa do Brasil. Brasília, DF: Senado Federal: Centro Gráfico, 1988.

BRASIL, Lei 9.985 de 18 de julho de 2000. Sistema Nacional de Unidades de Conservação (SNUC). Disponível em: $<$ https://www.mma.gov.br/estruturas/sbf corredores/ arquivos/snuc.pdf $>$. Acesso em: 10 set. 2020.

COMISSÃO MUNDIAL SOBRE MEIO AMBIENTE E DESENVOLVIMENTO (CMMAD). Nosso futuro comum. 1. Ed. Rio de Janeiro: Fundação Getúlio Vargas, 1988.

DRUCKER, P.F. on the Profession of Management. Harvard Business Review Book: Boston 1998.

FISCHER, T. Gestão do desenvolvimento e poderes locais: marcos teóricos e avaliação. Salvador: Casa da Qualidade, 2003.

FRANÇA FILHO, G.C. Gestão Social: Um Conceito em Construção. Anais do IX Colóquio Internacional Sobre Poder Local - II Colóquio Internacional El Análisis De Las Organizaciones Y La Gestión Estratégica: Perspectivas Latinas. Salvador-BahiaBrasil, 16 a 18 de junho de 2003.

FREITAS, E.R. de; BLANCO, M.S.S.G. Agroecologia: Conceitos. 2010. Artigo em Hypertexto. Disponível em: $<$ http://www.infobibos.com/Artigos/2010 2/agroecologia/index.htm>. Acesso em: 09 set. 2020.

GUIMARÃES, M. A Dimensão Ambiental Na Educação. Campinas, SP: Papirus, 1995.

MALDONADO, C. O turismo rural comunitário na américa latina: gênesis, características e políticas. In: BARTHOLO, R.; SANSOLO, D. G.; BURSZTYN, I. (org.). Turismo de base comunitária: diversidade de olhares e experiências brasileiras. Rio de Janeiro: Letra e Imagem, 2009. p. 25-44.

NETO, J.J.S.B. planejamento estratégico para o desenvolvimento sustentável do turismo rural no município de Lagoa Seca (PB). Disponível Em: $<$ http://livros01.livrosgratis.com.br/cp105397.pdf>. . Acesso em 29/03/2019.

OLIVEIRA, D.P.R. Planejamento Estratégico. 26ª ed., São Paulo: Atlas, 2009.

ORGANIZAÇÃO DAS NAÇÕES UNIDAS - ONU. Declaração sobre o Meio Ambiente Humano. Estocolmo, 1972. 
ORGANIZAÇÃO INTERNACIONAL TURISMO - OIT. Declaração de San José. San José, Costa Rica: Organização Internacional de do Turismo, 2003. Disponível em: $<$ http://www.redturs.org/inicio/docu/DeclaracionSan-Jose-Espa.pdf>. Acesso em: 08 set. 2020.

O'BRIEN, LEICHENKO, R. O'BRIEN, K.; SOLECKI, W. Climate Change and the Global Financial Crisis: A Case of Double Exposure. Forthcoming. In: Annals of the Association of American Geographers. 2010.

PENA, R.F.A. "Desenvolvimento sustentável"; Brasil Escola. Disponível em $<$ https://brasilescola.uol.com.br/geografia/desenvolvimento-sustentavel.htm>.

Acesso em 14 mar. 2019.

RAZETO, L. Lecciones de Economía Solidaria. Realidad, Teorí.a y Proyecto. Ediciones UVIRTUAL.NET, Santiago 2010 (tradução nossa). Disponível em: $<$ http://biblioteca2012.hegoa.efaber.net/registros/18411> , Acesso em 27 jul. 2020.

ROMAN, C. Para cumprir acordo internacional, Brasil precisaria reduzir desmatamento em 43\%. Instituto Socioambiental, 2018. Disponível em: $<$ https://www.socioambiental.org/pt-br/noticias-socioambientais/para-cumprir-acordointernacional-brasil-precisaria-reduzir-desmatamento-em-43>. Acesso em: 10 set. 2020.

\section{Notas:}

${ }^{1}$ Ditado popular

${ }^{2}$ Lei Federal ํㅜ 12.653/15.

${ }^{3}$ É uma ciência que fornece os princípios ecológicos básicos para o estudo e tratamento de ecossistemas tanto produtivos quanto preservadores dos recursos naturais, e que sejam culturalmente sensíveis, socialmente justos e economicamente viáveis, proporcionando assim, um agroecossistema sustentável. A abordagem agroecológica da produção busca desenvolver agroecossistemas com uma dependência mínima de insumos agroquímicos e energéticos externos.

4 "Agricultura cultivos de espécies vegetais úteis, sejam para a alimentação humana e animal, seja como matéria-prima para indústria têxtil, farmacêutica etc. Ex.: milho, feijão, hortaliças, arroz etc. Criação de animais - inclui todos os tipos de criação: bovinocultura/ pecuária tradicional, caprinocultura, ovincultura, suinocultura, piscicultura etc. Atividades de transformação - referem-se à transformação de matéria-prima vegetal ou animal de modo a agregar valor à produção agropecuária. Ex.: doces, farinha, mel, embutidos, cachaça, licores, sucos, vinho e bebidas em geral, polpas de frutas, queijos e outros derivados de leite etc. Atividades esportivas e de lazer. Eqüestres - abrangem atividades que envolvam a interação do homem com eqüinos (cavalo, jumento, burro e outros) para desempenho de alguma lida no campo ou para lazer, esporte e aventura." (BRASIL, 2010). 
Italo Schelive Correia: Universidade Federal do Tocantins, TO, Brasil.

E-mail: italo.schelive@uft.edu.br

Link para o currículo Lattes: http://lattes.cnpq.br/2679493489646247

Sandro Sidnei Vargas de Cristo: Universidade Federal do Tocantins, TO, Brasil.

E-mail: sidneicristo@uft.edu.br

Link para o currículo Lattes: http://lattes.cnpq.br/6004596653256447

João Paulo Carneiro dos Reis: Universidade Federal do Tocantins, TO, Brasil.

E-mail: bruno.simoes@uniriotec.br

Link para o currículo Lattes: http://lattes.cnpq.br/4575046970052301

Data de submissão: 15 de abril de 2019.

Data de recebimento de correções: 13 de dezembro de 2019

Data do aceite: 13 de dezembro de 2019

Avaliado anonimamente 